\title{
Monitoring the impact of litter in large vertebrates in the Mediterranean Sea within the European Marine Strategy Framework Directive (MSFD): constraints, specificities and recommendations
}

\author{
F. Galgani ${ }^{a, *}$, F. Claro $^{b}$, M. Depledge ${ }^{c}$, C. Fossi ${ }^{d}$
}

\author{
a Ifremer, Immeuble Agostini, ZI Furiani, 20600, Bastia, Corsica, FRANCE \\ ${ }^{\mathrm{b}}$ Museum national d'Histoire naturelle, GTMF, CP41, 57 rue Cuvier, 75231 Paris cedex 05, FRANCE \\ c University of Exeter, Devon EX4 4QJ, UNITED KINGDOM \\ d University of Siena, Via Mattioli 4, 53100 Siena , ITALY \\ *: Corresponding author : François Galgani, email address : francois.galgani@ifremer.fr
}

\begin{abstract}
:
In its decision (2010/477/EU) relating to the European Marine Strategy Framework Directive (MSFD, 2008/56/EC), the European Commission identified the following points as focuses for monitoring:

(i) 10.1.1: Trends in the amount, source and composition of litter washed ashore and/or deposited on coastlines,
\end{abstract}

(ii) 10.1.2: Trends in the amount and composition of litter in the water column and accumulation on the sea floor,

(iii) 10.1.3: Trends in the amount, distribution and composition of micro-particles (mainly microplastics), and

(iv) 10.2.1 Trends in the amount and composition of litter ingested by marine animals.

Monitoring the impacts of litter will be considered further in 2014. At that time, the strategy will be discussed in the context of the Mediterranean Sea, providing information on constraints, protocols, existing harm and research needed to support monitoring efforts.

The definition of targets and acceptable levels of harm must take all factors into account, whether entanglement, ingestion, the transport and release of pollutants, the transport of alien species and socio-economic impacts. It must also reflect on the practical deployment of "ingestion" measures (10.2.1). The analysis of existing data will reveal the potential and suitability of some higher trophic level organisms (fish, turtles, birds and mammals) for monitoring the adverse effects of litter. Sea turtles appear to be useful indicator species, but the definition of an ecological quality objective is still needed, as well as research on alternative potential indicator species. 


\section{Highlights}

- The paper links harm in larger vertebrates to the "ingestion" measures from the MSFD. D The paper analyses the suitability of larger vertebrates for monitoring. Sea turtles appear to be useful indicator species. Recommendations are given for both monitoring and research on litter ingestion.

Keywords : Marine litter ; MSFD ; Good Environmental Status ; Monitoring ; sea turtles ; marine mammals ; seabirds ; Fulmar

\section{Introduction}

The Mediterranean Sea is the planet's most highly-affected area in terms of marine litter, with densities of over 100,000 items/ha found on the sea floor, together with microplastics at 892,000 items $/ \mathrm{km}^{2}$ (Barnes et al., 2009; Collignon et al., 2012). In recent years, marine litter has caused increasing harm due to ingestion, entanglement and the transport of toxic or living organisms (Gregory, 2009).

In order to coordinate the protection of the marine environment, the European Commission has developed the Marine Strategy Framework Directive (MSFD) as part of its "Integrated Maritime Policy" (Marcus et al., 2011). This directive establishes a framework for each Member State to take action to achieve or maintain Good Environmental Status for the marine environment by 2020. Member States are obliged to follow an "action plan", including an initial assessment of current environmental status, determine what Good Environmental Status (GES) is, then establish a series of environmental targets and associated indicators.

The creation and implementation of a monitoring programme for ongoing assessment and regular target updating was launched recently. A series of measures designed to achieve or maintain good environmental status will complete the process by 2016 , with a follow-up assessment scheduled in 2018.

Among the 11 descriptors incorporating 56 indicators of Good Environmental Status, descriptor 10 is identified as "Properties and quantities of marine litter do not cause harm to the coastal and marine environment". "Litter" refers to items that have been made or used by people, then deliberately discarded or lost in the sea and on beaches, including material transported into the marine environment from land by rivers, drainage or sewage systems, or winds. Much of this litter will persist in the sea for years, decades or even centuries. On average, three quarters of all marine litter consists of plastics, which are known to be particularly persistent (Galgani et al., 2010).

The Commission's Decision (2010/477/EU) of September 1st, 2010 on "Criteria and methodological standards on Good Environmental Status of marine waters" identifies the following four indicators for monitoring progress towards achieving Descriptor 10: 
(i) Trends in the amount of litter washed ashore and/or deposited on coastlines, including analysis of its composition, spatial distribution and, where possible, source (10.1.1), (ii) Trends in the amount of litter in the water column (including floating at the surface) and deposited on the sea floor, including analysis of its composition, spatial distribution and, where possible, source (10.1.2), (iii) Trends in the amount, distribution and, where possible, composition of microparticles (in particular microplastics) (10.1.3), and (iv) Trends in the amount and composition of litter ingested by marine animals (e.g. stomach analysis) (10.2.1) for the evaluation of its impact on marine fauna organisms.

These Indicators were drawn up by a group of specialists on the basis of an assessment of what could be defined as Good Environmental Status (Galgani et al., 2010). However, knowledge relating to the distribution of litter, its degradation and fate, and its potentially harmful biological, physical and chemical impacts on marine life and habitats is currently insufficient.

Various monitoring programmes are to be implemented by 2014 . The definition of targets and acceptable levels of harm will mainly rely on the practical implementation of the "ingestion" indicators (10.2.1) listed in the MSFD. The strategy has been well-defined for indicators of adverse impacts in the Mediterranean Sea, but its limitations must be identified and its scientific basis must be made more robust. UNEP pointed out that the main legal and institutional frameworks affecting the Mediterranean on this topic underline a general lack of available data on marine wildlife affected by marine litter in the Mediterranean Sea.

Marine litter has a major impact on large vertebrates, as animals often become entangled in discarded ropes and nets, or trapped in plastic containers and strapping bands. Many animals also mistake litter items as prey: up to $76 \%$ of turtles have been recorded as ingesting plastic bags in certain Mediterranean areas (Tomas et al., 2002), while the stomachs of $98 \%$ of Fulmars in the North Sea have been found to contain plastic, potentially leading to a loss of physical condition, breeding failure and, in severe cases, to death (Van Franeker et al., 2011). Mediterranean seals and other marine mammal species are subject to entanglement, but large vertebrates may also be exposed to micro-litter ingestion through passive ingestion, in particular filter feeding (Fossi et al., 2012).

The analysis of existing data reveals the potential and suitability of some higher trophic level organisms as indicators for monitoring the effects of litter (figure 1). Here, we describe the opportunities and limitations of using large vertebrates to evaluate the harm caused to marine life by litter. We also highlight several key issues that must be addressed through research. Finally, various recommendations are given to support the implementation of monitoring programs. 


\section{MSFD AND THE MONITORING OF MARINE LITTER}

In Article 11 of the monitoring requirements of the MSFD, it is specified that Member States must establish and implement coordinated monitoring programmes for the ongoing assessment of the environmental status of their marine waters and that monitoring programmes within given marine regions or sub-regions must be compatible.

The monitoring efforts will address various objectives, such as the assessment of GES, temporal and spatial trends, the level of achievement of environmental targets and the effectiveness of measures. Monitoring will mainly consists of determining trends in the amounts of marine litter and its adverse impacts, and the identification of sources, in order to support measures to reduce plastic inputs. Indicators that are to be directly included in national monitoring plans in 2014 and indicators requiring further development will typically be considered separately.

In the context of the Mediterranean sea and Barcelona Convention, a Policy Document and associated Strategic Framework for Marine Litter management was adopted through MEDPOL in 2012 to (i) follow trends of marine litter generation and distribution through the establishment of a monitoring programme for marine litter based on the Ecosystem Approach, (ii) indicate sources and activities leading to marine litter production, and (iii) indicate if the adopted litter management/mitigation strategies are effective or need further adaptation.

A litter monitoring programme is expected to be developed for the application of the Ecosystem Approach at a regional level, with MEDPOL coordinating this activity and promoting the appropriate methodologies. The Regional Action Plan (RAP) on marine litter, adopted in December 2013, shall become legally binding once it has been adopted by the Contracting Parties of the Barcelona Convention. Article 12 of the RAP refers to a Mediterranean Marine Litter Monitoring Programme for 2014, following international and regional guidelines adapted from the protocols produced by the MSFD technical group on marine litter (Galgani et al., 2011; MSCG TG Marine Litter, in preparation). This technical group tackles the comparison and final assessment of the various existing monitoring methods, as well as other crucial issues that must be addressed and clarified (spatial distribution of survey sites, sampling frequency, QA/QC needs, management/handling of data/metadata, etc.).

The impacts of nano and microplastics at sea span many biological levels, from molecular to ecosystem. They include chemical and mechanical impacts due to ingestion, the release of 
transported chemicals and the transport of alien species (Fossi et al., 2012, Cole et al., 2013; Rochman et al., 2013). Entanglement by, and ingestion of, larger debris generally affect large organisms, whether on an individual or population level. However, larger debris may also affect smaller organisms and ecosystems through transportation to new, remote habitats, albeit to a lesser extent.

Biota indicators play an important role, as they provide indications of possible harm. At the same time, current protocols and methods have varying degrees of maturity. Pilot-scale monitoring is therefore an important step towards monitoring litter harm in terms of determining baselines and/or adapting the strategy to local areas. Regarding harm assessment in the Mediterranean sea, and in accordance with Article 11 of the MSFD, Member States sharing a marine region or sub-region must also draw up their monitoring programmes in a coherent manner by ensuring monitoring methods are consistent across the marine region or sub-region; this will facilitate the comparison of monitoring results and take into account relevant trans-boundary impacts and features. Without some degree of information on trends and amounts across all compartments, a risk-based approach to litter monitoring and measures is impossible.

When defining the aims and objectives of monitoring, the Marine Strategy Coordination Group (MSCG) interpreted monitoring as an assessment of whether GES has been achieved or maintained, whether environmental status is improving, stable or deteriorating, and what progress has been made towards achieving environmental targets.

Our current lack of knowledge with regards to harmful levels of litter is such that absolute targets are difficult to set; as a result, many Member States are formulating trend targets instead. The protocol for litter ingested by Fulmars (van Franeker, 2011a \& b) is an exception: a quantitative target level has been formulated as an OSPAR Ecological Quality Objective (EcoQO) and has recently become a legal obligation in certain member states. The design of most protocols enables regional adaption and the discrimination of litter items; they are therefore likely to detect changes in litter types and enable a proper assessment of the various measures implemented. For example, monitoring of litter in Fulmar stomachs in the OSPAR area has shown decreasing trends in industrial plastic pellets after measures were taken to decrease pellet spillage (Galgani et al., 2011). As major future decisions will be based on measures, monitoring efforts should be shouldered by quality control/quality assurance (inter-comparisons, use of reference material, training, etc.) to assist survey teams. A master-standard list of categories of litter items has been prepared by the MSCG Technical Group ML with compatible sub-categories for the various marine compartments (beach, sea floor, sea surface and ingested litter). This will enable the comparison of results between regions and environmental compartments. Items may be attributed to a given source e.g. fisheries, shipping etc., or a given form of interaction e.g. entanglement, ingestion 
etc., hence facilitating identification of the main sources of marine litter pollution and the potential harm caused by litter. This will enable a more target-orientated implementation of measures.

Site selection strategies will focus on both sites with specific characteristics and sites chosen randomly in order to facilitate extrapolations. Regarding harm indicators in larger organisms from the Mediterranean sea, the implementation of sampling campaigns on species (turtles, fish, mammals or birds) that are widely distributed and may migrate over long distances, while taking into account the characteristics of the sampling area (generally on a basin/subbasin level), will assist in creating a large-scale monitoring network catering for transboundary issues, despite the difficulties and costs involved in finding statisticallysignificant trends. Moreover sampling/analysis will need to be coordinated and harmonized on a basin scale, e.g. Northwestern Mediterranean, Adriatic, Ionian, Aegean and Levantine basins.

Our ability to unveil significant trends or variations may be assisted by case-specific statistical power analysis. This has been conducted for various protocols, e.g. the Fulmar litter ingestion protocol, and increases the probability of detecting actual changes.

Data handling and reporting for the MSFD are under consideration both at an EU level and a Regional Sea and sub-regional level. An online, European-wide data collection system will facilitate analysis. The reporting process for data and information under the MSFD (Art 19.3) is being addressed by the DIKE Working Group (Data, Information Knowledge Transfer) and steered by DG Environment and the European Environmental Agency, to define data that will be collected at a national level and made available through INSPIRE or EMODnet in the framework of the Water Information System for Europe (WISE-Marine).

\section{ADVERSE IMPACTS AND MONITORING}

The potentially harmful implications of marine litter have escalated in recent years and currently include: (i) harm to and mortality of marine wildlife as a consequence of the ingestion of in marine litter, (ii) entanglement in derelict nets, traps and pots leading to potential losses in biodiversity, (iii) the accumulation and transport of persistent organic pollutants and the release of potentially toxic and hormonal-effective chemicals, and (iv) transport of alien species (Gregory, 2009).

Defining harm in the MSFD context is a difficult task. A variety of approaches or guidelines can be used to evaluate the adverse effects of litter at sea. Reference documents such as the UK government's Farm Animal Welfare Council, which takes into account 5 types of effects, named freedoms, are useful (FAWC, 1979). However, we do not possess a complete 
picture of the effects of marine litter. Moreover, its economic impacts, as referred to in the GES definition, are not taken into consideration in this approach.

Litter affects marine life at various organisational levels and its impact varies according to the target species or population, environmental conditions and the considered region or country. The concept of harm itself is not obvious, as no acceptable units of measure have been defined. A reassessment of what Good Environmental Status means will help better define harm within MSFD. However, even proven harm may not be useful for monitoring purposes. In view of the diversity of litter and targets, measurements may prove unsuitable for the large-scale, complex harmonisation currently necessary.

For example, entanglement has been highlighted as having one of the most harmful impacts on marine organisms, with culprits such as strapping bands, plastic bags and drums. As a result of their size and weight, larger vertebrates may continue to travel over considerable distances after becoming entangled in ropes, net and lines, hence transforming active fishing gear into marine debris. Reports also exist of small cetaceans, such as harbour porpoises, becoming entangled in ghost fishing gear (Butterworth et al., 2012). However, the MSFD monitoring criteria only refer to ingested litter, due to difficulties in distinguishing between entanglement in litter and active fishing gear. The European situation with regards to animal deaths due to entanglement is somewhat diverse. In certain areas, with efficient stranding networks, entangled beached species such as cetaceans are quite frequently found and could therefore contribute to harm assessment. However, current difficulties in interpreting data, together with the low reported numbers of entangled beached animals and problems associated with large-scale harm assessment due to the rarity of strandings, mean this approach can only usefully be applied to specific areas and on the basis of national decisions. Nevertheless, research may contribute to the development of new, more specific entanglement indicators. For example, seabird nests can be used to facilitate litter-related entanglement monitoring, as the litter found there cannot originate from active fishing gear (Votier et al., 2011), Optimising this type of protocol should promote a better understanding of harmful effects and more efficient MSFD implementation in the future.

An emerging area of concern is the accumulation of microplastic fragments (less than $5 \mathrm{~mm}$ ) in the water column and in sediment, which also affect marine life and especially filter feeders (Thompson et al., 2004).

Several recent studies have identified the potential effects of plastic particles, in particular on invertebrates and fish, including: 1 - transport of persistent, bioaccumulating and toxic (PBT) substances from plastics. 2- leaching of additives from the plastics such as phthalates. 3physical harm (Wright, et al. 2013). 
However, until the recent work of Fossi et al. (2013), no data had been reported on the impact of microplastics on large filter-feeding organisms such as baleen whales or sharks, which potentially ingest micro-litter while filter feeding.

As no single species can actually provide full coverage of all of Europe's maritime zones, a range of species is needed to monitor ingested litter, possibly with some spatial overlaps. An indicator expressing the impact of marine litter is available in the North Sea (OSPAR EcoQO); it is used to measure ingested litter in the Northern Fulmar (Fulmarus glacialis) with regards to a set target for acceptable ecological quality in the North Sea (van Franeker et al. $2011 a$ \& b). This tool is applicable to most Northeast Atlantic countries, but research (proportions of micro and macro debris found in stomachs, particles sizes, etc.) is needed, especially for the Mediterranean Sea, and further afield if possible. On the basis of available information and expertise, the MSCG TG ML group reported on the development of monitoring protocols for other species of seabirds, sea turtles and fish. A similar approach to the Fulmar approach has been suggested, whereby various plastic categories are counted and weighed.

A protocol for sea turtle monitoring, focusing on various parameters, is currently being developed for application in the Mediterranean Sea and some areas of the South Atlantic Sea. As post-mortem examinations reveal litter in 30-80\% of endangered Loggerhead sea turtles Caretta caretta (IUCN red list status "Endangered A1abd ver 2.3", IUCN 2013 and species listed in CITES Appendix I, review in Schuyler et al., 2013) stranded on beaches or accidentally captured in the northern area of the Western Mediterranean (Claro \& Hubert, 2011; Pibot \& Claro 2011), on the western coast of Italy (Travaglini et al., 42\%, N=60 \& Cameda et al., 30\%, $\mathrm{N}=30$, this issue), in the Adriatic Sea (Lazar and Gracan, 2011), and on the coasts of Tuscany (Campani et al. 2013) and Spain (Tomas et al 2002), this species is a good candidate for monitoring the Mediterranean on a sub-basin scale (Northwestern Mediterranean, Adriatic, Ionian, Aegean and Levantine basins). This protocol will need to be further improved through (i) more efficient networks dedicated to the collection of stranded animals and measurement of the impact of fishing gear, (ii) the collection of information from rescue centres, (iii) special consideration of $M L$ information from existing monitoring efforts, (iv) the consideration of new findings and ( $v$ ) monitoring the effects of litter in living organisms using a non-destructive biomarker approach. A pilot study evaluating methods and potential sources of bias was conducted in 2012 in Italy (Matiddi et al., 2012). Research must now be performed to define a Sea Turtle EcoQO suitable for the various areas in the context of the MSFD. This may also constitute an objective for Southern OSPAR regions (France, Spain and Portugal). 
The overall threat incurred by ingested macroplastics and other debris remains unclear with regards to all populations and cetacean species. Debris ingestion in 43 cetacean species has been reported in the literature, comprising 7 Mysticete and 35 Odontocete species (Baulch and Perry, 2012; IWC, 2013). However, if we look at research on the ingestion of debris by marine mammals, even in view of the spectacular cases of mortality due to ingestion of large amounts of marine litter in the Mediterranean Sea (Jacobsen et al., 2010, De Stefanis et al., 2013), the known rates of incidence of ingested litter are generally too low to justify a standard MSFD monitoring recommendation. For example, less than $1 \%$ of mammals stranded on French beaches between 1972 and 2006 were found to have ingested litter (Pibot \& Claro, 2011). However, we do have an adequate understanding of variations in species distribution and behaviour at different times of the year, which can be extremely valuable integrators of environmental quality. Discussions at the SETAC workshop in 2013 (Fossi et al., 2012b) revealed that large pelagic fish may be especially useful for monitoring short to medium-term changes in pelagic ecosystems, while marine mammals such as whales provided a more integrated view in the long term (Fossi et al., 2012).

Although these are early days for suggesting a particular protocol and assessing ongoing research activity, the MSFD marine litter TSG identified the need to develop a common protocol for the monitoring of ingested litter in fish, applicable at all sites, as a priority. Information is still required on the size/types of items to be examined and fish species that are suitable from an ecosystem perspective and for regional comparison (abundance, cycles, etc.). Regular fish monitoring campaigns are already conducted in the Mediterranean Sea (http://www.sibm.it/SITO\%20MEDITS/ and pelagic fish surveys), involving shared sampling efforts and using tried and tested protocols derived from methods for analysing the content of fish stomachs (Cortes, 1997).

Plastic ingestion by seabirds has been widely recorded, being Procellariiformes the most affected order (Rodriguez et al., 2012). Despite the voluminous information on ingested plastic debris by adults across the world (Van Franeker et al., 2011 a \& b; Rodriguez et al., 2012), only one study described however plastic ingestion in Mediterranean seabirds (Codina-Garcia et al., 2013). With occurrences of debris in 70 to $94 \%$ of individuals, when the rest of species were below $33 \%$ the results pointed out the threatened shearwater species as being particularly exposed to plastic accumulation. Implementation of monitoring may be however limited because of the distribution of these three endemic species, restricted to the western Mediterranean sea.

If abundance of ingested debris by seals has been mentioned as a potential indicator of marine litter in the European Marine Strategy Framework Directive, a recent study (BravoRebolledo et al., 2013) demonstrated however an incidence on $11 \%$ of the harbour seal from the Dutch coast. In the Mediterranean sea where fewer than 600 individuals of 
Monachus monachus are remaining, no study has been performed but if observed level of incidence may be of environmental concern, the distribution is patchy and the abundance is low in the sense of suitability for monitoring purposes.

In addition to ingestion protocols, guidelines are currently being developed for litter in seabird nest structures and the associated entanglement in litter in nest structures. Some species tend to incorporate marine litter in their nests, which may result in entanglement (Votier et al., 2011). Although regional occurrence and distribution vary, nesting material and associated mortalities can be linked to the amounts of litter found in the natural environment in the vicinity of the breeding site, hence demonstrating the harmful effects of litter with more ease versus litter ingestion. Monitoring can continue to focus on existing colonies that are regularly monitored in many European countries without too much extra effort, but research is still needed to define behaviours, breeding seasons and the types of litter brought into seabird nests, in particular any litter that may originate from land. Information is grossly lacking on Mediterranean nesting species such as European shags (Phalacrocorax aristotelis), but the potential remains important, especially with regards to monitoring of remote islands.

The European Shag is very common throughout the Mediterranean and nests on coastal areas in most European and North African countries, together with the Black Sea coast. Litter in shags' nests is already used as indicator of marine pollution in Brittany, France (Cadiou et al., 2011) and the protocol may serve as a basis for implementing the MSFD .

Only a limited number of reports exist on microparticle sampling in biota. Most of these relate to small organisms. Among the larger vertebrates, baleen whales and, potentially, basking sharks are exposed to micro-litter ingestion as a result of their filter-feeding activity, but impacts are under investigation (Fossi et al., 2012a). These large, filtering marine organisms were recently selected for the MED-SDSN PLASTIC-BUSTERS project (under the UN umbrella) as wide-scale indicators of the presence and impact of microplastics throughout the Mediterranean pelagic environment. The fin whale (Balaenoptera physalus), which is one of the largest filter feeders in the world, feeds primarily on planktonic euphausiid species. This whale, which is the only resident mysticete in the Mediterranean Sea, gathers in the feeding grounds of the Pelagos Sanctuary Marine Protected Area (MPA). With each mouthful, the whales trap approximately 70,000 I of water, and their feeding activities include surface feeding. The basking shark (Cetorhinus maximus) is a large, filter-feeding, migratory and widely-distributed pelagic species. Basking sharks feed on zooplankton captured by forward swimming with an open mouth, so that a passive water flow passes across the gillraker apparatus. Both species could face risks due to the ingestion and degradation of microplastics. The recent workshop (May 2013) organized by the International Whaling Commission (IWC) at the Woods Hole Oceanographic Institution recommended that baleen 
whales and other large filter feeders be considered in national and international marine debris strategies (e.g. Descriptor 10 (marine litter) in the EU Marine Strategy Framework Directive) as critical indicators of the presence and impact of microplastics in the marine environment. As this is the only example of microplastic ingestion by large vertebrates and the first warning of this emerging threat to baleen whales, and despite the difficulties of sampling, this approach must be considered for further investigation.

Plasticizers, sealing agents and additives such as phthalates or bisphenol $A$ have been shown to be present in the tissues of various marine organisms, including large vertebrates such as whales and sharks (Fossi et al., 2012 a \& b). Their presence in tissues such as blubber from stranded fin whales (Balaenoptera physalis) or muscle from basking sharks (Cetorhinus maximus) suggests that they could serve as a tracer of microplastic intake.

However, although these plastic derivatives have major potential toxicity, their monitoring in the MSFD framework is typically associated with Descriptor 8.

\section{RESEARCH}

In addition to the identification of sources and monitoring-based support, a better understanding of the harm to large marine vertebrates caused by marine litter is needed to support Member States in the implementation of Descriptor 10. However, there is no consolidated common understanding of what constitutes "harm" from marine litter, or how it can be assessed. Research efforts to develop robust approaches for harm assessment will need to be identified. The identification of gaps in our understanding and the development of research programmes are key prerequisites, so that monitoring tools and protocols can be implemented realistically and cost-effectively.

The recent workshop (May 2013) organized by IWC also encouraged further non-lethal research in view of the promising research on biomarker development. It recommended further work in this field, such as new gene expression biomarkers in cetaceans developed in an "ex vivo" approach (organotypic cultures), which exposes cetacean skin biopsies to increasing doses of contaminant mixtures.

Many European projects got underway in 2012/2013. Some have now been completed, but most are still in progress with projected results in 2014-2015. The EC is currently defining the research programmes for Horizon 2020, in which MSFD marine litter research must be taken into account. Priority should be given to the most-affected areas, the most prominent of which is probably the Mediterranean Sea. As stated by the MSCG Technical Group regarding impacts and ingestion, monitoring implementation and short-term research priorities will need to (i) Develop or use existing comprehensive models to define source and destination regions of litter (especially accumulation areas), (ii) Evaluate the environmental 
consequences of litter-related chemicals (Phthalates, bisphenol A, etc.) in marine organisms using specific diagnostic biomarkers, (iii) Establish the environmental consequences of micro-litter to establish potential physical and chemical impacts on wildlife, (iv) Evaluate the effects of litter on metabolism, physiology, survival rate, reproductive performance and, ultimately, on populations or communities, (v) Study dose/response relationships in relation to types and quantities of marine litter, to enable science-based definitions of threshold levels, and (vi) Rationalise monitoring (standards/baselines; data management/quality assurance; extend monitoring protocols to all Mediterranean sub-regions).

The development and implementation of assessment and monitoring campaigns, and the implementation of measures in the framework of the Mediterranean Action Plan, will also require scientific cooperation among the Parties involved. The Secretariat of the Barcelona convention will organize and support this scientific cooperation, advise the EU Project in terms of scientific needs and support action on priority research topics. In view of the common concerns of the MSCG TG with regards to harm monitoring, research priority will be given to (i) The development of comprehensive modelling tools for the evaluation and identification of sources and fate of litter in the marine environment, (ii) Effects (lethal or sub lethal) under different environmental conditions of entanglement, in particular on threatened and protected species, (iii) Understanding how litter ingested by marine organisms, in particular threatened and protected species, affects their physiological condition and chemical burden, reduces survival and reproductive performance and ultimately affects their populations or communities, and (iv) Developing an Ecological Quality Objective (EcoQO) for ingestion of litter in indicator species suitable for monitoring (sea turtles).

\section{CONCLUSIONS}

In view of our current level of understanding of the harm to marine life caused by marine litter and the potential of large vertebrates for assessing Good Environmental Status, the above recommendations may help support the implementation of monitoring in the MSFD framework.

\section{Insert table 1}

\section{REFERENCES}

Butterworth, A., Clegg, I., Bass, C., 2012. Marine debris: a global picture of the impact on animal welfare and of animal-focused solutions. WSPA International, 222 Grays Inn Road, London, WC1X 8HB, WSPA International, 222 Grays Inn Road, London, WC1X 8HB. 
Cadiou, B., Pouline, P., Dugue, L., 2011. Occurrence of marine debris in European shag's nests as indicator of marine pollution. Poster presented at the Seabird Group 11th International Conference, 2-4 September 2011, Plymouth, UK.

Claro, F., Hubert, P., 2011. Impact des macrodéchets sur les tortues marines en France métropolitaine et d'Outre-mer. Rapport GTMF-SPN 1. MNHN-SPN, Paris, 52p.

Codina-García, M., Militão, T., Moreno, J., J González-Solís, J., 2013. Plastic debris in Mediterranean seabirds. Marine Pollution Bulletin 77, 1-2, 220-226.

Cole, M., Lindeque, P., Fileman, E, Halsband, C., Goodhead, R., Moger, J., T.Galloway 2013. Micro-plastic ingestion by zooplankton. Environmental Science \& Technology, 47 (12), 6646-6655.

Cortes, E., 1997. A critical review of methods of studying fish feeding based on analysis of stomach contents: application to elasmobranch fishes. Can J Fish Aquat Sci 54, 726-738.

Dantas, D., Barletta, M. and da Costa, M., 2011. The seasonal and spatial patterns of ingestion of polyfilament nylon fragments by estuarine drums (Sciaenidae). Environ. Sci. Poll. Res. 19(2), $600-606$.

De Stephanis R., J. Giménez, E. Carpinelli, C.Gutierrez-Exposito, A Cañadas, 2013. As main meal for sperm whales: Plastics debris. Marine Pollution Bulletin, 96, 206-214.

Farm Animal Welfare Council, FAWC (1979) http://www.fawc.org.uk/freedoms.htm

Fossi, M., Giannetti, M., Guerranti, C., Marsili, L., Coppola, D., Panti, C., Minutoli, R.,2012. Are baleen whales exposed to the threat of microplastics? A case study of the Mediterranean fin whale (Balaenoptera physalus). Marine Pollution Bulletin 64(11), 2374-9.

Fossi, M., Guerranti, C., Coppola, D., Baiani, M., Giannetti, M., Campani, T., Clo, S., Desabata, S., 2012a. Preliminary assessment of microplastics threat in Mediterranean basking sharks (Cetorhinus maximus): Implication for the MSFD. Poster presented at the International Conference on Prevention and Management of Marine litter, 10-12/04/2013.

Fossi, C., Casini, S., Caliani, I., Panti, C., Marsili, L. Viarengo, A.,Giangreco, R., Notarbartolo di Sciara, N., Serena, F., Ouerghi, A., Depledge, M., 2012b. The role of large marine vertebrates in the assessment of the quality of pelagic marine ecosystems. Marine Environmental Research 77, 156-158.

Galgani, F., Fleet, D., Van Franeker, J., Katsavenakis, S., Maes, T., Mouat, J., Oosterbaan, L., Poitou, I., Hanke, G., Thompson, R., Amato, E., Birkun, A. \& Janssen, C., 2010. Marine Strategy Framework Directive Task Group 10 Report Marine litter, JRC Scientific and technical report, ICES/JRC/IFREMER Joint Report (no 31210 - 2009/2010), Editor: N. Zampoukas , $57 \mathrm{pp}$.

Galgani, F., Hanke, G., Werner, S., Piha, H., 2011. MSFD GES Technical Subgroup on Marine Litter. Technical Recommendations for the Implementation of MSFD Requirements. JRC scientific and technical report, EUR 25009 EN - 2011, 93 pp.

Gregory, M.R.,2009. Environmental implications of plastic debris in marine settings entanglement, ingestion, smothering, hangers-on, hitch-hiking, and alien invasions. Philosophical Transactions of the Royal Society B 364, 2013-2026,

doi:10.1098/rstb.2008.0265. 
International Whaling Commission (IWC) 2013. Report of the 2013 IWC Scientific Committee workshop on Marine Debris. Woods Hole Oceanographic Institution, may 13-17 2013, SC/65a/Rep06, 39 pages.

\section{IUCN 2013 : http://www.iucnredlist.org/details/3897/0}

Jacobsen, J.K., Massey, L., Gulland, F., 2010. Fatal ingestion of floating net debris by two sperm whales (Physeter macrocephalus). Marine Pollution Bulletin 60, 765-767.

Lazar, B., Gracan, R., 2011. Ingestion of marine debris by loggerhead sea turtles, Caretta caretta, in the Adriatic Sea. Marine Pollution Bulletin 62, 43-47.

Markus, T., Schlake, S., Maier, N. 2011. Legal Implementation of Integrated Ocean Policies: The EU's Marine Strategy Framework Directive. Int. J.of Mar.Coast.Law 26, 59-90.

Matiddi M., van Franeker J.A., Sammarini V., Travaglini A., Alcaro L., 2011. Monitoring litter by sea turtles: an experimental protocol in the Mediterranean. Proceedings of the 4 th Mediterranean Conference on Sea Turtles. 7-10 November, Naples.

Pibot, A., Claro, F., 2011. Impacts écologiques des déchets marins dans les Sous-régions marines du Golfe de Gascogne et de Méditerranée. Reports of the French MSFD initial assessment, SRM MO \& GDG, 12 \& 13 pages, http://wwz.ifremer.fr/dcsmm/Le-Plan-dAction-pour-le-Milieu-Marin/Evaluation-initiale/Contributions-thematiques.

Possatto, F.E., Barletta, M., Costa, M.F., Sul, J.A.I.d. and Dantas, D.V., 2011. Plastic debris ingestion by marine catfish: An unexpected fisheries impact. Marine Pollution Bulletin 62, 1098-1102.

Schuyler, Q., Hardesty, B.D., Wilcox, C., Townsend, K. 2013. Global analysis of anthropogenic ingestion by sea turtles. Conservation Biology, doi: 10.1111/cobi.12126.

Bravo Rebolledo, E., Van Franeker, J., Jansen, O., Brasseur, S., 2013. Plastic ingestion by harbour seals (Phoca vitulina) in The Netherlands. Mar. Poll. Bull. 67, 200-202.

Rochman, C., Hoh, E., Kurobe, T., Teh, S. (2013) Ingested plastic transfers hazardous chemicals to fish and induces hepatic stress. Nature, Scientific Reports, 3, Article 3263, doi:10.1038/srep03263

Rodríguez, A., Rodríguez, B., Nazaret Carrasco, M., 2012. High prevalence of parental delivery of plastic debris in Cory's shearwaters (Calonectris diomedea) Marine Pollution Bulletin 64 (2012) 2219-2223.

Thompson, R.C., Olsen, Y., Mitchell, R.P., Davis, A., Rowland, S.J., John, A.W.G., McGonigle, D. \& Russell, A. E., 2004. Lost at sea: where is all the plastic? Science 304, 838. (doi:10.1126/science.1094559)

Tomas,J., Guitart, O., Mateo, R., Raga, J.A., 2002. Marine debris ingestion in loggerhead sea turtles, Caretta caretta,from the Western Mediterranean. Marine Pollution Bulletin 44 211-216.

Van Franeker, J.A., Blaize, C., Danielsen, J., Fairclough, K., Gollan, J., Guse, N., Hansen, P.L., Heubeck, M., Jensen, J.-K., Le Guillou, G., Olsen, B., Olsen, K.O., Pedersen, J., Stienen, E.W.M. \& Turner, D.M. 2011a. Monitoring plastic ingestion by the northern fulmar Fulmarus glacialis in the North Sea. Environmental Pollution 159, 2609-2615. 
doi:10.1016/j.envpol.2011.06.008

Van Franeker, J.A. \& the SNS Fulmar Study Group, 2011b. Fulmar Litter EcoQO monitoring along Dutch and North Sea coasts in relation to EU Directive 2000/59/EC on Port Reception Facilities: results to 2009. IMARES Report Nr C037/11. IMARES, Texel, 52pp +2app.

Votier, S.C., Archibald, K., Morgan, G., Morgan, L. 2011. The use of plastic debris as nesting material by a colonial seabird and associated entanglement mortality. Marine Pollution Bulletin 62, 168-172.

Figure 1 caption: Summary of interactions between large marine vertebrates and marine litter. Fluxes of litter in the life cycle and intensity of its effects on large marine vertebrates, (1a: entanglement; 1b: ingestion), depending on various factors such as ingestion mechanisms (predation, active or passive filter feeding), development stage (benthic or pelagic phases for sea turtles), behaviour and foraging strategy (feeding on the sea floor, in the water column or on the surface, selectivity according to colour, shape etc, ecological plasticity in diet and habitat), types of litter (micro/macro litter) and types of fishing gear (nets, hooks and lines). The thicker arrows indicate key processes. Although trophic transfer from one level to another has been demonstrated in vitro for microplastics in plankton, it remains controversial in situ, as most ingested litter is excreted in faeces. 
Table 1 : Recommendations for monitoring and research on litter ingestion by large marine organisms within MSFD.

\section{A) Monitoring}

\section{Turtles (high priority):}

- Define an EcoQO for the loggerhead turtle Caretta caretta in the Mediterranean sea (High priority)

- Organize monitoring at sub regional (basin level) in an harmonised manner

- Improve the collection of information/samples (stranded turtles and from fishermen)

\section{Birds:}

- Evaluate the potential value of nested litter as an indicator for the evaluation of GES and as a monitoring tool

\section{Fish:}

- Evaluate the potential value of fishes for monitoring the ingestion of litter by marine organisms

\section{B) Research}

\section{Birds:}

- Identify bird species suitable for the development of a Fulmar type EcoQo

- Better understand impacts of litter on nesting birds

\section{Turtles:}

- Better understand migrations of turtles in the Mediterranean. 
- Better understand how litter is affecting organisms (digestion, physiology, reproduction, population dynamics, etc.)

\section{Mammals and sharks:}

- Understand interactions between long term marine environmental changes and litter effects on mammals for the assessment of the quality of pelagic marine ecosystems

- Mammals: investigate how microplastics cause harm to large filter feeders

\section{Overriding:}

- Evaluate types and size of litter ingested in relation to the stage of development 
Fig 1a: entanglement

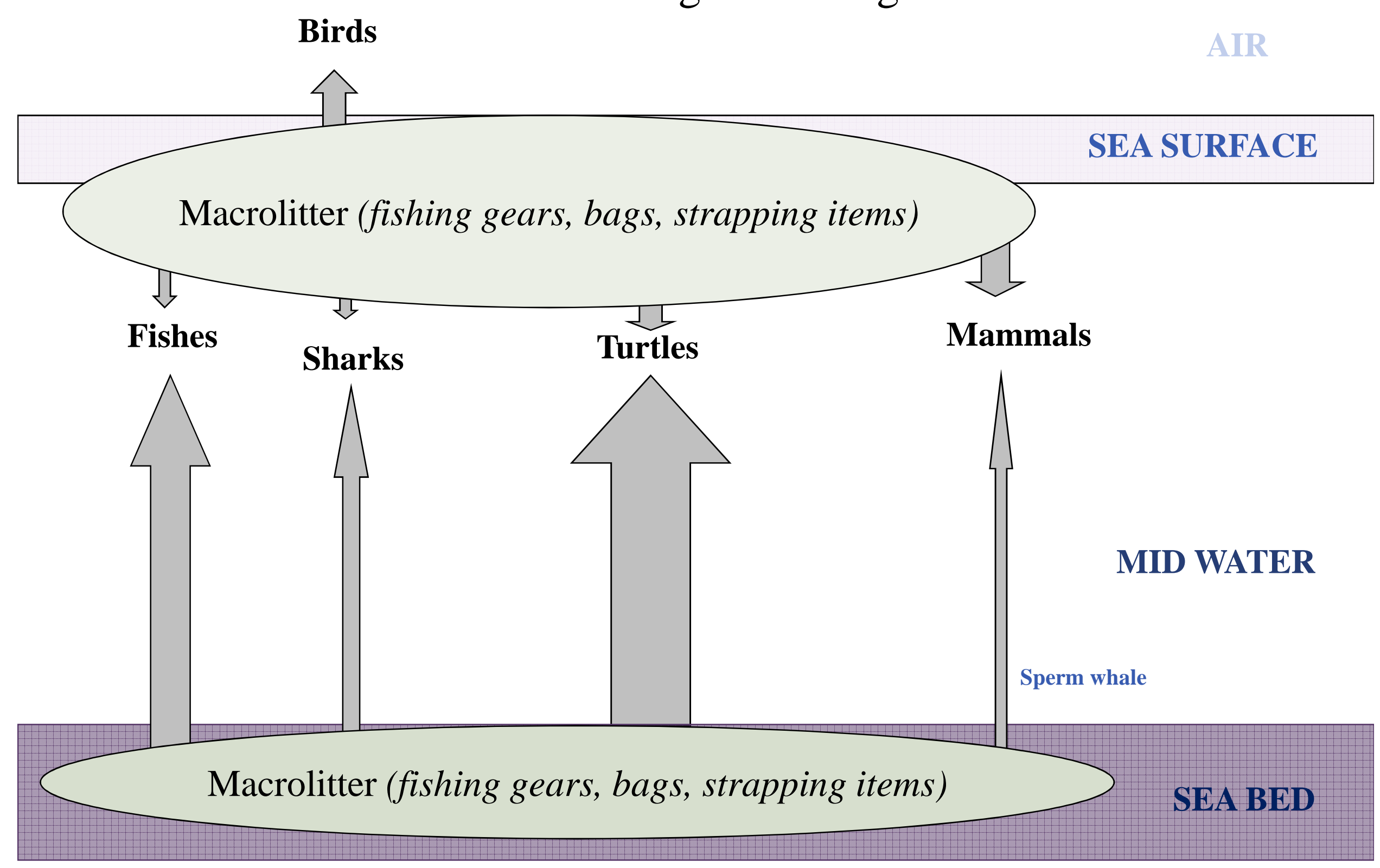




\section{Fig. 1b: ingestion}

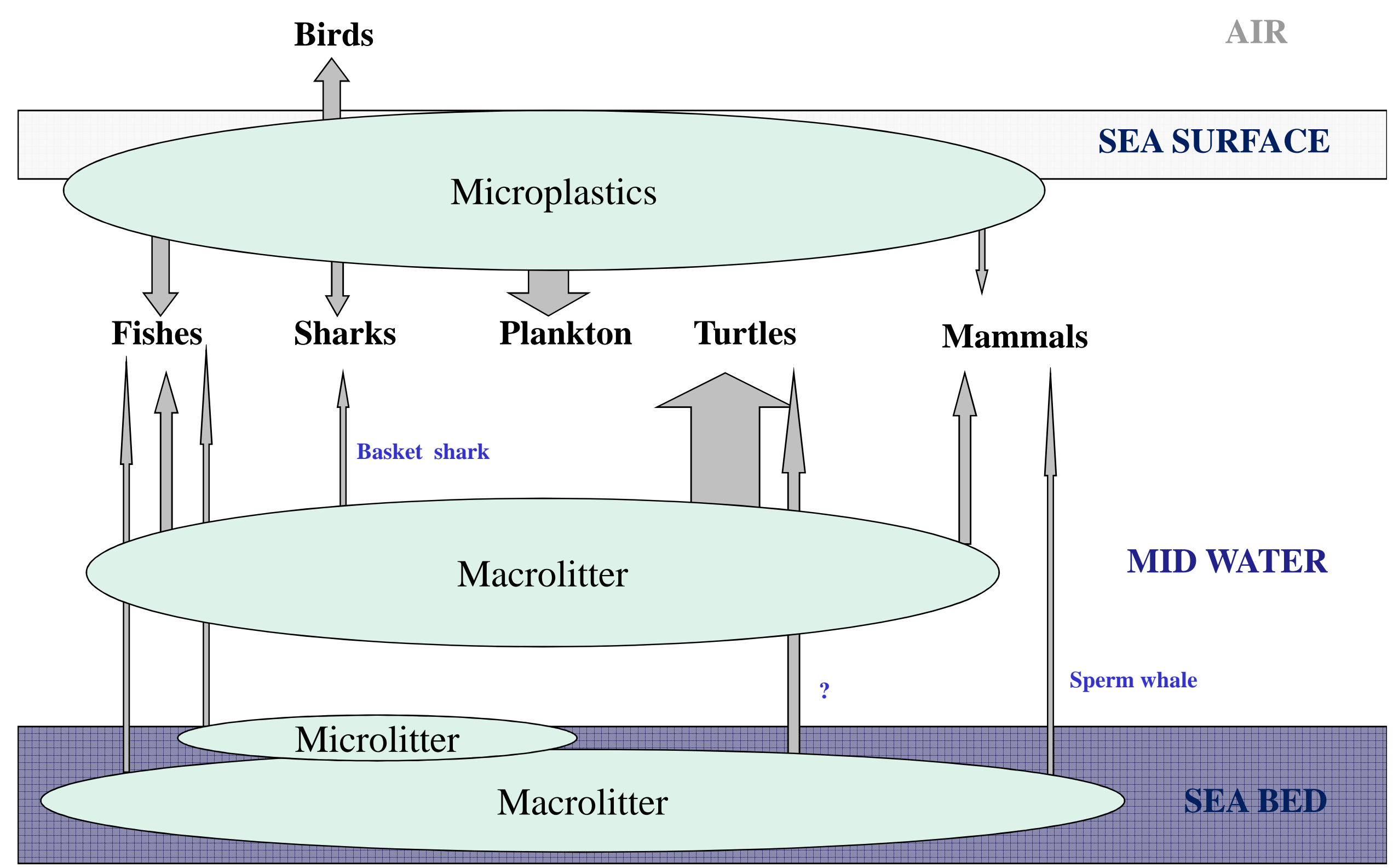

